\title{
Statistical Process Control Improves The Feasibility Of Remote Physiological Monitoring In Patients With Chronic Obstructive Pulmonary Disease
}

This article was published in the following Dove Press journal: International Journal of Chronic Obstructive Pulmonary Disease

\author{
Christopher B Cooper' \\ Worawan Sirichana ${ }^{1,2}$ \\ Eric $\bigvee$ Neufeld (D) \\ Michael Taylor ${ }^{3}$ \\ Xiaoyan Wang ${ }^{4}$ \\ Brett A Dolezal ${ }^{1}$ \\ 'Exercise Physiology Research \\ Laboratory, Departments of Medicine \\ and Physiology, David Geffen School of \\ Medicine, University of California, Los \\ Angeles, CA, USA; ${ }^{2}$ Division of \\ Pulmonary and Critical Care Medicine, \\ Department of Medicine, Chulalongkorn \\ University, Bangkok, Thailand; ${ }^{3}$ Research \\ Technology Inc., Philadelphia, PA, USA; \\ ${ }^{4}$ Division of General Internal Medicine \\ and Health Services Research, David \\ Geffen School of Medicine, University of \\ California, Los Angeles, CA, USA
}

Correspondence: Christopher B Cooper David Geffen School of Medicine, University of California, 10833 Le Conte Avenue, 37-131 CHS Building, Los Angeles, CA 90095-1690, USA

Tel + I 310 4703983

$\mathrm{Fax}+13102068211$

Email ccooper@mednet.ucla.edu
Background: Exacerbations of chronic obstructive pulmonary disease (COPD) occur with increasing frequency as the disease progresses and account for poor health status, worse prognosis, and higher healthcare expenditure.

Methods: We developed a networked system for remote physiological monitoring (RPM) at home and optimized it with statistical process control (SPC) with the goal of earlier detection of COPD exacerbations. We enrolled 17 patients with moderate to severe COPD with a mean (SD) age of 71.1 (7.2) years. We obtained daily symptom scores, treatment adherence and activity levels using a programmable device, and measured daily slow and forced spirometry $\left(\mathrm{FEV}_{1}, \mathrm{FVC}, \mathrm{PEF}\right)$, inspiratory capacity (IC) and oxygenation $\left(\mathrm{SpO}_{2}\right)$. To identify exacerbations, we developed rolling prediction intervals for $\mathrm{FVC}, \mathrm{FEV}_{1}, \mathrm{IC}$ and $\mathrm{SpO}_{2}$ using $\mathrm{SPC}$. Results: The time taken to perform daily monitoring was reduced from 12.7 (5.4) minutes to 6.5 (2.6) minutes through software refinements during the study. Adherence to forced and slow spirometry was $62.6 \%$ and $62.4 \%$, respectively. The within-subject coefficients of variation for $\mathrm{FEV}_{1}, \mathrm{PEF}$ and IC were $12.2 \%, 16.2 \%$, and $13.1 \%$, respectively. Event rates per patient-year for exacerbations were: self-reported 0.42, 2/3 Anthonisen Criteria (AC) 0.42 , modified AC 2.23, systemic corticosteroid use 0.56, and antibiotic use 0.56 .

Conclusion: We successfully implemented a networked system for RPM of symptoms, treatment adherence, and physiology at home in patients with COPD. We demonstrated that SPC improves the feasibility of RPM in COPD patients which may increase the likelihood of detecting COPD exacerbations.

Keywords: chronic obstructive pulmonary disease exacerbations, early detection, treatment adherence, home monitoring

\section{Introduction}

Chronic Obstructive Pulmonary Disease (COPD) is a major health problem and a leading cause of disability and mortality throughout the world. ${ }^{1-3}$ The disease is characterized by chronic airway inflammation and airflow obstruction that is partially reversible on administration of inhaled bronchodilator therapy. Disease progression is usually defined by progressive worsening of airflow obstruction or the rate of decline in forced expiratory volume in 1 second $\left(\mathrm{FEV}_{1}\right)$. However, it is well recognized that $\mathrm{FEV}_{1}$ alone does not fully characterize the disease and that there are many phenotypes and extra-pulmonary comorbidities. Disease progression is also characterized by an increasing frequency of exacerbations and these exacerbations are associated with significant morbidity, mortality and increased healthcare 
utilization. There is also some evidence to suggest that those patients with more frequent exacerbations tend to have a more rapid decline in lung function and clear evidence that patients with lower $\mathrm{FEV}_{1}$ tend to have more exacerbations. ${ }^{4,5}$ Exacerbations are also associated with poor quality of $\operatorname{life}^{6}$ and earlier recognition and intervention in exacerbations could improve outcomes and result in a better quality of life. ${ }^{7}$ Appropriate exacerbation management, prevention and early intervention are the goals for COPD treatment. There are many interventions that aim to reduce exacerbation frequency in COPD, for example, vaccinations and maintenance therapy with inhaled medications. A proactive management strategy that focusses on early detection of exacerbations could lead to earlier treatment which could, in turn, lessen the severity and consequences of the exacerbation.

Information technology offers interesting possibilities in terms of telemedicine or remote patient monitoring at home. Remote monitoring has been deployed in patients with chronic heart failure aiming to reduce healthcare utilization and improve quality of life. ${ }^{8,9}$ Since COPD is complex disease with multiple physiological changes during an exacerbation, remote patient monitoring should include both symptoms and physiological measurements. Daily spirometry has been performed at home in several studies. ${ }^{10,11} \mathrm{FEV}_{1}$, forced vital capacity (FVC) and peak expiratory flow (PEF) have been shown to be decreased during periods of exacerbations. ${ }^{12,13}$ However, inspiratory capacity (IC) was not routinely used for daily monitoring due to inadequate data on reliability and reproducibility. Thus, remote patient monitoring remains a challenge in COPD with a need to develop network management and to evaluate feasibility and adherence to monitoring. The questions that need to be answered are: how often should patients be monitored to detect symptoms of clinical deterioration and which parameter(s) should be included in remote patient monitoring? Ultimately, one would hope that remote patient monitoring could be used to investigate interventions that could be deployed to minimize exacerbation severity and perhaps decrease hospitalization and other aspects of healthcare utilization.

Our aim was to study the feasibility of remote physiological monitoring (RPM) in COPD in terms of data capture and data reliability. In the course of the study, we introduced statistical process control (SPC), an approach used in engineering for quality assurance, to help identify significant signals or predictors. We have demonstrated that statistical process control (SPC) can improve its effectiveness in monitoring COPD patients.

\section{Materials And Methods}

\section{Study Design}

This was a prospective study to develop and evaluate a system for daily remote monitoring of COPD patients including physiological measurements and questionnaires.

\section{Study Population, Inclusion And Exclusion Criteria}

We enrolled 17 subjects who lived within a reasonable traveling distance to University of California, Los Angeles (UCLA). The enrollment criteria were as follows: age $>40$ years and a clinical diagnosis of moderate to severe COPD in accordance with the American Thoracic Society (ATS) definition, ${ }^{14}$ a smoking history $>10$ pack-years, postbronchodilator $\mathrm{FEV}_{1} / \mathrm{FVC}<70 \%$ and $\mathrm{FEV}_{1}<70 \%$ based on NHANES III reference values. ${ }^{15}$ Subjects were expected to be taking inhaled maintenance therapy for COPD and their domestic situation had to be considered conducive to remote patient monitoring. Subjects were excluded if they had concurrent pulmonary disease other than COPD, e.g., lung cancer, active tuberculosis, bronchiectasis unrelated to COPD, pulmonary fibrosis, or cystic fibrosis. We excluded those with any other disease that carried a prognosis less than 2 years, those with a recent history of myocardial infarction (within 6 weeks of enrollment), a COPD exacerbation within 6 weeks of enrollment or had a known or suspected history of drug or alcohol abuse within 2 years prior to the initial visit. This investigation was approved by the UCLA Institutional Review Board and all participants provided written informed consent. The study was conducted in accordance with the Declaration of Helsinki.

\section{Baseline Assessment}

All subjects performed baseline assessments at the UCLA Exercise Physiology Research Laboratory which included: (i) Medical history and physical examination, (ii) documentation of COPD medications, and (iii) 12-lead supine electrocardiogram.

Spirometry was performed in accordance with new ATS/ERS standards ${ }^{16,17}$ in the seated position with nose clip applied after the subject had rested for at least $10 \mathrm{~min}$. Forced and slow spirometry maneuvers were performed under the supervision of certified pulmonary function technologist using a portable electronic spirometer (SpiroPro ${ }^{\circledR}$. ERT, Inc. Philadelphia, PA). During the baseline visit, subjects were trained to use the spirometer themselves and also learned how to transfer data via modem. 
General health-related quality of life was determined at baseline and final visits using the Medical Outcomes Trust Short Form 12 questionnaire (SF-12). ${ }^{18}$ Disease-specific quality of life (for COPD patients) was determined using the COPD Assessment Test (CAT). ${ }^{19}$ The St. George Respiratory Questionnaire was also administered to assess the quality of life. ${ }^{20}$

\section{Remote Patient Monitoring Daily Routine}

Subjects who participated in the study were asked to perform daily monitoring using SpiroPro ${ }^{\circledR}$. This device is an FDA-approved handheld spirometer that was also programmed with electronic diaries, questionnaires and the capability for recording pulse oximetry. Measured values were $\mathrm{FEV}_{1}, \mathrm{FVC}, \mathrm{PEF}, \mathrm{IC}$ and pulse oximetry $\left(\mathrm{SpO}_{2}\right)$. Novel questionnaires included questions on daily symptoms such as cough, breathlessness, wheezing, sputum volume and purulence (CLEAR-Sx), daily physical activities (CLEAR-Ex), and questions on daily medications (CLEAR-Rx). Healthcare utilization, in terms of physician visits, emergency department visits and hospitalizations, was also captured electronically during monthly telephone follow-up by the study coordinator. The expected monitoring routine is shown diagrammatically in Figure 1. Subjects were required to transfer data via modem every

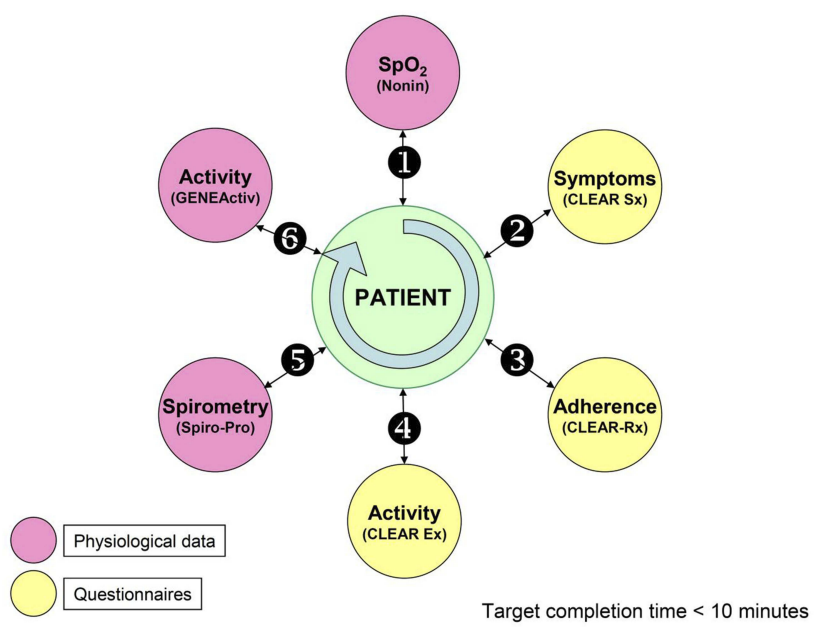

Figure I Schema for daily remote patient monitoring.

Notes: Patients were asked to seat themselves at a table in front of the monitoring equipment. They then applied the finger pulse oximeter. They were then taken through a series of screens which presented questions about their symptoms (CLEAR-Sx), treatment adherence (CLEAR-Rx) and physical activity (CLEAR-Ex). Next, they performed an inspiratory capacity maneuver followed by a forced vital capacity maneuver. Finally, they removed the pulse oximeter. The target completion time was set at 10 mins.
1-3 days through a secure UCLA network system to the UCLA Exercise Physiology Research Laboratory.

After about 6 months of experience with the study procedures, we were able to analyze feedback from our subjects on the ease of performing the stipulated maneuvers. It was evident that the standard requirement of performing at least three acceptable tests according to the ATS/ERS standard ${ }^{17}$ was too arduous on a daily basis and was compromising patient adherence to the protocol. At this stage, we modified the analytical software using and introduced statistical process control (SPC). This change allowed subjects to perform only one or two forced maneuvers each day of monitoring provided that one of the maneuvers was technically acceptable and could be evaluated along with sequential maneuvers performed on preceding days (Figure 2). Details of the SPC deployed are shown in Appendix A. The refined analytical software was available 10 months after the start of the study for all subjects undergoing remote monitoring. There were five subjects that used both the old and new analytical software.

\section{Activity Monitoring}

For each subject assigned to remote monitoring, we tracked daily physical activity using a commercially available tri-axial accelerometer (GENEActiv ${ }^{\circledR}$. Kimbolton, UK). Data were continuously recorded for $24 \mathrm{hrs,} \mathrm{every}$ day, at $40 \mathrm{~Hz}$ frequency and analyzed in 60-s epochs. The sum of vector magnitudes was computed with gravity subtracted (SVMgs).

$$
\operatorname{SVMgs}=\sum\left|\sqrt{x^{2}+y^{2}+z^{2}}-g\right|
$$

The GENEActiv ${ }^{\circledR}$ accelerometers were exchanged every 2 weeks by mail with pre-addressed and pre-paid envelopes and data were extracted with the goal of continuing until 12 months of data had been accumulated.

\section{Monthly Telephone Contact}

During the study, a study coordinator from the UCLA Exercise Physiology Research Laboratory made a monthly phone call to each subject. Data obtained from these monthly phone calls included the CAT questionnaire, changes of medication, and any self-reported exacerbation events which had necessitated healthcare utilization.

\section{Definition Of Predictors}

Predictors were considered to be significant findings from remote monitoring. Since this was primarily a feasibility 
SPC : Technically acceptability

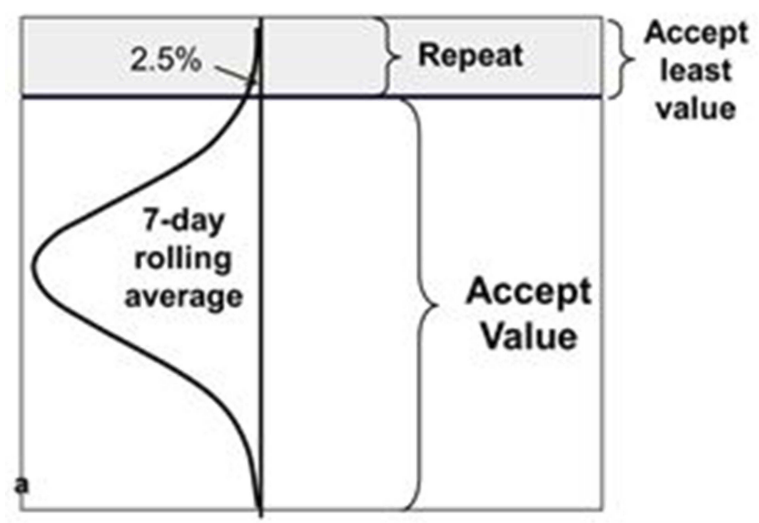

SPC : Clinical event detection

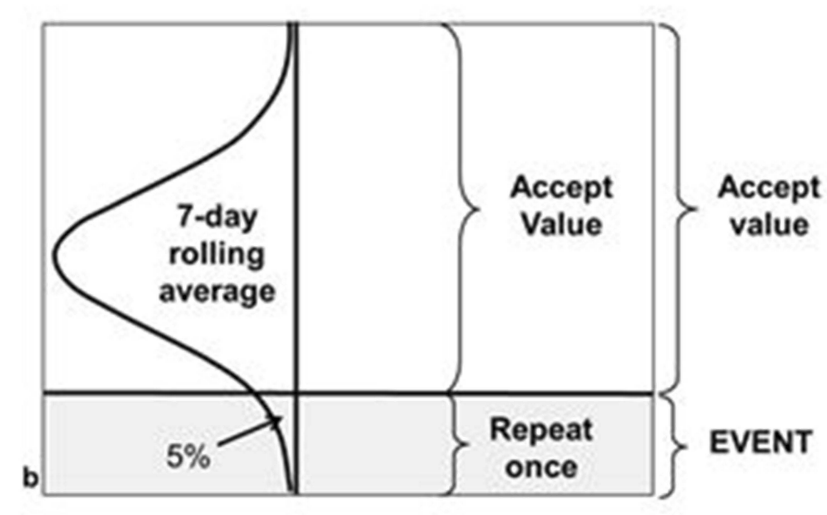

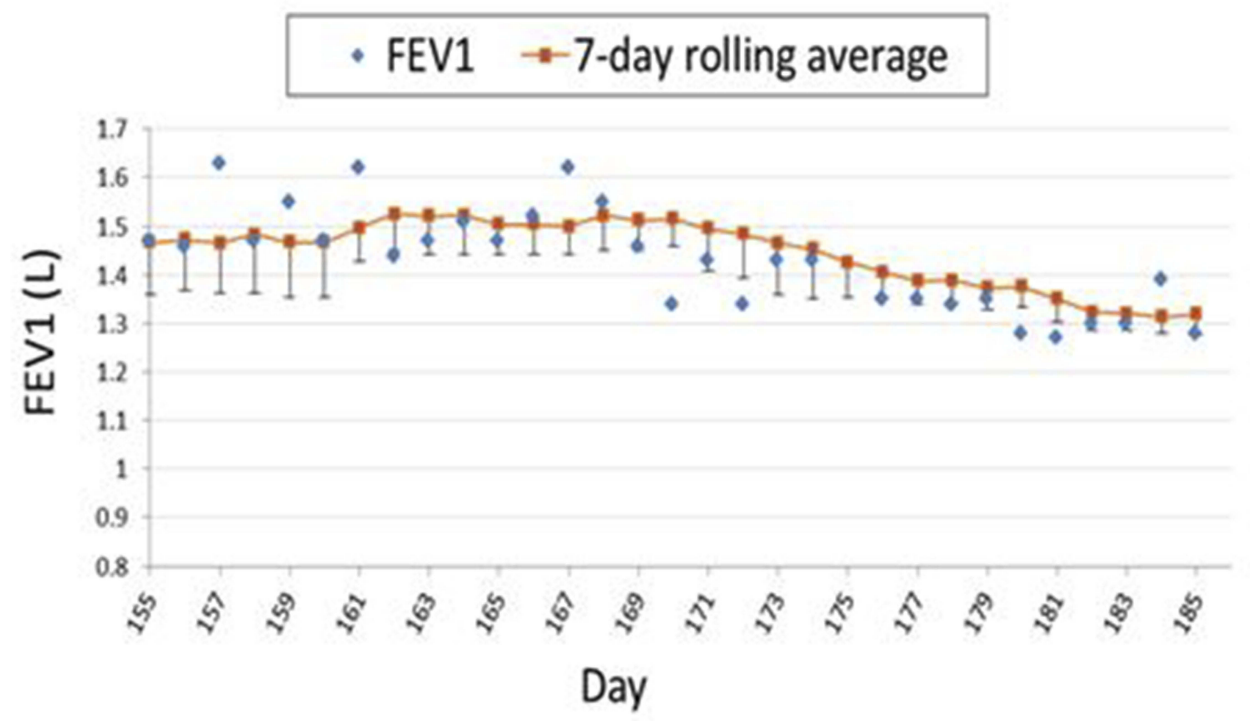

Figure 2 Diagrammatic representation of the statistical process control monitoring algorithm.

Notes: The 7-day rolling average for each physiological variable was tracked along with the standard deviation and prediction interval. Whenever a daily recorded value exceeded the 2-sided $95 \%$ prediction interval, then it was considered technically unacceptable and repeated. The lower of the two values was then captured. Whenever a daily recorded value fell below the I-sided $95 \%$ prediction interval, then it was repeated and if still below the I-sided $95 \%$ prediction interval, then it was considered to be a clinical event.

study, the interpretation of the data remained exploratory. We used several thresholds to define prediction events from responses to questionnaires or from physiological measures.

\section{Pulse Oximetry}

A fall in $\mathrm{SpO}_{2}$ below $90 \%$ for 2 consecutive days or a fall below the 7 -day rolling average minus $4 \%$ for 2 consecutive days. Taking into account the known accuracy of the instruments, a $4 \%$ fall in $\mathrm{SpO}_{2}$ is considered clinically meaningful.

\section{Spirometry}

A fall in $\mathrm{FEV}_{1}, \mathrm{FVC}, \mathrm{PEF}$ or IC lower than the 7-day rolling average minus one $\mathrm{SD}$ for two consecutive days or lower than the 7-day rolling average minus $1.645 \mathrm{SD}$ for 2 consecutive days. The latter criterion represents a onesided $95 \%$ prediction interval.

\section{Inactivity}

Self-reported lack of any physical activity for two consecutive days from responses to the CLEAR-Ex.

\section{Discontinuation Of Maintenance Therapy}

Self-reported failure to take prescribed long-acting inhaled maintenance therapy (LAMA and/or LABA) for two consecutive days by CLEAR-Rx.

\section{Use Of Short-Acting Inhaled Bronchodilators}

An increase in self-reported use of short-acting inhaled bronchodilators (SABA or SAMA) by two actuations 
above the 7-day average for that subject at the time of enrolment into the study by CLEAR-Sx (period of clinical stability).

The end of positive predictor signal was identified if the value for each predictor had returned to within the prediction interval based on the previous 7-day average, for 2 consecutive days.

\section{Definition Of Outcomes}

The outcome of interest which we wished to detect by remote monitoring was exacerbations. However, these could be defined in several different ways.

\section{Self-Reported Exacerbation}

A reported exacerbation was an event reported by the subject during monthly telephone calls with the study coordinator. Typically, these events were associated with reported changes in medications such as inhaled bronchodilators, antibiotics or systemic corticosteroids. Office visits, emergency department visits and hospitalization were also included in this category of outcomes. However, only one enrolled subject-reported hospitalizations (three times) but this subject did not receive $\mathrm{RPM}$.

\section{Anthonisen Criteria}

An increase over two consecutive days in three out of three symptoms (breathlessness, sputum volume and sputum purulence) as captured by CLEAR-Sx using the 7-day rolling average plus 1.645 SD as the threshold (Anthonisen Class 1). ${ }^{21}$ An increase over two consecutive days in at least two out of three symptoms (breathlessness, sputum volume and sputum purulence) as captured by CLEAR-Sx using the 7day rolling average plus 1.645 SD as the threshold (Anthonisen Class 2).

\section{Modified Anthonisen Criteria}

An increased over two consecutive days of two major symptoms (breathlessness, sputum volume and sputum purulence) or increased one major symptom plus one minor symptom (cough or wheezing) as captured by CLEAR-Sx using the 7-day rolling average plus 1.645 $\mathrm{SD}$ as the threshold (Modified Anthonisen Criteria).

\section{Use Of Antibiotic}

Self-reported use of any antibiotic for worsening respiratory symptoms from responses to the CLEAR-Sx.

\section{Use Of Systemic Corticosteroid}

Self-reported use of systemic corticosteroids such as prednisone for worsening respiratory symptoms from responses to the CLEAR-Sx.

\section{Data Analysis \\ Descriptive Statistics}

Mean and standard deviation was used to describe baseline demographic and clinical characteristics.

\section{Feasibility}

The operational feasibility of remote monitoring system was analyzed by compliance rate (number of days with successfully transferred data divided by the total number of days of remote patient monitoring). In addition, time spent performing daily maneuvers was captured.

\section{Adherence}

A daily adherence score was calculated by summation of successfully transferred values for each monitoring maneuver $\left(\mathrm{SpO}_{2}\right.$, slow vital capacity, forced vital capacity, CLEAR-Sx, CLEAR-Ex, CLEAR-Rx). One point was allocated for each successfully transferred data element giving a maximum possible score of 6 for each day of monitoring. The maneuvers included in the analysis are:

(a) Oxygen saturation recorded or not ( $1=$ recorded, $0=$ not recorded);

(b) Slow spirometry recorded or not $(1=$ recorded, $0=$ not recorded);

(c) Forced spirometry recorded or not $(1=$ recorded, $0=$ not recorded);

(d) Daily symptoms recorded or not $(1=$ recorded, $0=$ not recorded);

(e) Daily activity recorded or not $(1=$ recorded, $0=$ not recorded);

(f) Daily treatment recorded or not $(1=$ recorded, $0=$ not recorded)

\section{Comparison Of Analytical Software Versions}

For each maneuver and adherence score, a two-way frequency table was generated according to whether data were recorded or not and whether the analytical software was old or new (refined). Counts and percentages were reported. A Chi-squared test was performed to test if the different versions of the software were associated with different compliances.

A subset analysis was performed on five subjects in our study who used both versions of the software. A paired 
$t$-test was used to compare the percentages of recorded maneuvers or averaged adherence scores between the new and the old software. The paired subset analysis allowed us to further assess any difference in study compliance between the old and new versions of software by eliminating possible individual differences that occur between subjects.

\section{Results \\ Study Population}

We enrolled 17 subjects for remote patient monitoring (RPM). Six subjects did not provide any data and three discontinued monitoring partway through the 12-month target monitoring period. These subjects collectively provided 2618 days of data home monitoring or 7.17 patientyears. Interestingly, 12 of the 17 subjects were women which might suggest that men are less likely to agree to home monitoring. After 10 months of monitoring, we began using a refined version of the analytical software. The reason for this change was based on challenges with patient adherence to the stringent criteria which had been applied for the performance of spirometry (described below). ${ }^{17}$ Following the change, four enrolled subjects were monitored using only the new software. The total monitoring time was 1398 patient-days with the old software and 1220 patient-days with the new software. Nine subjects withdrew from the study; five withdrew their consent before starting remote monitoring and one was lost to follow up. There were three subjects who began RPM but dropped out during the study. We included their incomplete monitoring data in our analysis.

\section{Baseline Characteristics}

The baseline characteristics for the subjects are shown in Table 1. Their mean (SD) age was 71.1 (7.2) years and five $(29.4 \%)$ were men. Baseline $\mathrm{FEV}_{1}$ was 1.54 (0.73) L or 56.8 (15.9) \% predicted. FVC was 3.04 (1.09) L or 86.8 (14.1) \% predicted. $\mathrm{FEV}_{1} / \mathrm{FVC}$ was $50.7 \%$. In other words, on average, the subjects had moderate COPD by GOLD spirometric classification. The median (range) score for the COPD Assessment Test (CAT) was 13 (range 5-25) positioning most of the subjects as highly symptomatic according to the latest GOLD grading. ${ }^{14}$ Health status scores were 36.4 (4.7) by the Short Form-12 and 28.0 (13.9) by the St George's Respiratory Questionnaire (SGRQ). These findings categorize the subjects as having mildly to moderately compromised health status.
Table I Baseline Assessments For Subjects Undergoing Remote Patient Monitoring

\begin{tabular}{|l|l|}
\hline Measure & Baseline (n= I7) \\
\hline Age (years) & $71.1(7.2)$ \\
Sex (male, N, \%) & $5(29.4 \%)$ \\
FEV I (L) & $1.54(0.73)$ \\
FEV $\%$ predicted & $56.8(15.9)$ \\
FVC (L) & $3.04(1.09)$ \\
FVC \% predicted & $86.8(14.1)$ \\
PEF (L/m) & $4.84(2.59)$ \\
PEF \% predicted & $70.0(27.3)$ \\
CAT* & $13(5-25)$ \\
SF-I2 & $36.4(4.7)$ \\
SGRQ & $28.0(13.9)$ \\
\hline
\end{tabular}

Notes: Data are presented as mean (SD). *Data are presented as median (range). Abbreviations: $\mathrm{FEV}_{1}$, forced expiratory volume in one second; FVC, forced vital capacity; PEF, peak expiratory flow; CAT, Chronic Obstructive Pulmonary Disease (COPD) Assessment Test; SF-12, Short Form 12 questionnaire; SGRQ, St. George's Respiratory Questionnaire.

Daily physical activity ( $\Sigma \mathrm{A})$ was quantitated as the sum of vector magnitude units with gravity subtracted (SVMgs) from the tri-axial accelerometers (GENEActiv, Kimbolton, UK). The mean (SD) $\Sigma$ A was $114.2(18.7) \mathrm{g} \cdot \mathrm{min}$. The mean (SD) activity time per day (non-sedentary) was 162.8 (57.7) minutes and $99 \%$ of this time was classified as light intensity (1.5-2.9 METs). There was no correlation between $\Sigma \mathrm{A}$ and CAT $(r=0.042, \mathrm{P}=0.800)$ or between $\Sigma \mathrm{A}$ and baseline $\mathrm{FEV}_{1}$ $(\mathrm{r}=0.148, \mathrm{P}=0.363$ ). Unfortunately, we could not identify activity patterns immediately before or after an exacerbation event since there was poor subject adherence with wearing the accelerometer in relation to any of these events.

\section{Adherence To Daily Monitoring}

During the initial 10-month phase of this study, we found adherence to the remote monitoring routine to be less than satisfactory. Allocating one point for complete data transfer for each of oxygen saturation, forced spirometry, slow spirometry, CLEAR-Sx, CLEAR-Rx and CLEAR-Ex, we observed an average score of only 3.3 points (out of a possible total score of 6 ) over 1,398 days of monitoring (Table 2). At this point, we refined the software used for collation and analysis of the data based on principles of SPC (Appendix A). With these refinements, the adherence score increased to 4.3 points (Table 2 ) and the proportion of monitoring days with higher adherence scores increased substantially (Appendix B). For example, the proportion of monitored days with an adherence score of 6 increased from $50.1 \%$ to $69.4 \%$. Completion of each component of monitoring before and after the introduction of the refined 
Table 2 Summary Of Adherence To Each Component Of Remote Monitoring

\begin{tabular}{|l|l|l|}
\hline & $\begin{array}{l}\text { Old Software } \\
\text { (1398 Patient-Days) }\end{array}$ & $\begin{array}{l}\text { New Software } \\
\text { (1 220 Patient-Days) }\end{array}$ \\
\hline $\mathrm{SpO}_{2}$ & $755(54.0 \%)$ & $849(69.6 \%)$ \\
$\mathrm{CLEAR-Sx}$ & $768(54.9 \%)$ & $880(72.1 \%)$ \\
CLEAR-Rx & $768(55.0 \%)$ & $880(72.1 \%)$ \\
CLEAR-Ex & $764(54.7 \%)$ & $880(72.1 \%)$ \\
Slow spirometry & $754(53.9 \%)$ & $880(72.1 \%)$ \\
Forced spirometry & $762(54.5 \%)$ & $878(72.0 \%)$ \\
Adherence score & $3.3(2.9)$ & $4.3(2.7)$ \\
(total = 6) & & \\
\hline
\end{tabular}

Abbreviations: $\mathrm{SpO}_{2}$, oxygen saturation; CLEAR-Sx, daily symptom reporting; CLEAR-Rx, daily medication reporting; CLEAR-Ex, daily physical activity.

software was examined using Chi-squared tests. Adherence to pulse oximetry increased from $54.0 \%$ to $69.6 \%(\mathrm{P}<0.001$, Table 3$)$. Adherence to daily symptom reporting by CLEAR-Sx increased from $54.9 \%$ to $72.1 \%$
$(\mathrm{P}<0.001$, Table 3$)$. Adherence to daily medication reporting by CLEAR-Rx increased from $55.0 \%$ to $72.1 \%$ $(\mathrm{P}<0.001$, Table 3). Adherence to daily physical activity reporting by CLEAR-Ex increased from $54.7 \%$ to $72.1 \%$ $(\mathrm{P}<0.001$, Table 3). Adherence to slow spirometry increased from $53.9 \%$ to $72.1 \%(\mathrm{P}<0.001$, Table 3$)$. Adherence to forced spirometry increased from $54.5 \%$ to $72.0 \%(\mathrm{P}<0.001$, Table 3$)$.

Looking at the subset of five subjects who experienced both the old and new versions of the analytical software, we also saw significant improvements in adherence for all components of monitoring $(\mathrm{P}<0.001$, Table 4). Subset adherence to pulse oximetry increased from 49.0 (14.2) $\%$ to $84.1(8.4) \%(P=0.006$, Table 5). Subset adherence to daily symptom reporting by CLEAR-Sx increased from 50.0 (14.2) \% to $87.0(9.8) \%(\mathrm{P}=0.011$, Table 5). Subset adherence to daily medication reporting by CLEAR-Rx increased from 50.0 (14.2) \% to 87.0 (9.8) \% ( $\mathrm{P}=0.011$,

Table 3 Breakdown Of Adherence To Each Component Of Remote Monitoring

\begin{tabular}{|c|c|c|c|c|}
\hline Component Of Remote Monitoring & Reported & Old Software (\%) & New Software (\%) & Chi-Squared P-value \\
\hline \multirow[t]{3}{*}{ Oxygen Saturation $\left(\mathrm{SpO}_{2}\right)$} & No & $643(46.0 \%)$ & $371(30.4 \%)$ & \multirow[t]{2}{*}{$<0.001$} \\
\hline & Yes & $755(54.0 \%)$ & $849(69.6 \%)$ & \\
\hline & Total Days monitored & 1,398 & 1,220 & \\
\hline \multirow[t]{3}{*}{ Daily Symptom Reporting (CLEAR-Sx) } & No & $630(45.1 \%)$ & $340(27.9 \%)$ & \multirow[t]{2}{*}{$<0.001$} \\
\hline & Yes & $768(54.9 \%)$ & $880(72.1 \%)$ & \\
\hline & Total Days Monitored & 1,398 & 1,220 & \\
\hline \multirow[t]{3}{*}{ Daily Medication Reporting (CLEAR-Rx) } & No & $630(45.1 \%)$ & $340(27.9 \%$ & \multirow[t]{2}{*}{$<0.001$} \\
\hline & Yes & $768(54.9 \%)$ & $880(72.1 \%)$ & \\
\hline & Total Days Monitored & 1,398 & 1,220 & \\
\hline \multirow[t]{3}{*}{ Daily Physical Activity Reporting (CLEAR-Ex) } & No & $634(45.4 \%)$ & $340(27.9 \%)$ & \multirow[t]{2}{*}{$<0.001$} \\
\hline & Yes & $764(54.7 \%)$ & $880(72.1 \%)$ & \\
\hline & Total Days Monitored & I,398 & 1,220 & \\
\hline \multirow[t]{3}{*}{ Slow Spirometry Monitoring } & No & $644(46.1 \%)$ & $340(27.9 \%)$ & \multirow[t]{2}{*}{$<0.001$} \\
\hline & Yes & $754(53.9 \%)$ & $880(72.1 \%)$ & \\
\hline & Total Days Monitored & 1,398 & 1,220 & \\
\hline \multirow[t]{3}{*}{ Forced Spirometry Monitoring } & No & $636(45.5 \%)$ & $342(28.0 \%)$ & \multirow[t]{2}{*}{$<0.001$} \\
\hline & Yes & $762(54.5 \%)$ & $878(72.0 \%)$ & \\
\hline & Total Days Monitored & 1,398 & 1,220 & \\
\hline
\end{tabular}

Notes: Overall, participants on new software demonstrated better:

- Oxygen saturation monitoring compliance $(69.59 \%$ reported) than those on the old software $(54.01 \%$ reported) $(P<0.000 \mathrm{I})$.

- Daily symptom reporting compliance $(72.13 \%$ reported) than those on the old software $(54.94 \%$ reported) $(\mathrm{P}<0.000 \mathrm{I})$.

- Daily treatment reporting compliance $(72.13 \%$ reported) than those on the old software $(54.94 \%$ reported $)(P<0.000 \mathrm{I})$.

- Daily activity reporting compliance $(72.13 \%$ reported) than those on the old software $(54.65 \%$ reported) $(P<0.0001)$.

- Slow spirometry monitoring compliance $(72.13 \%$ reported) than those on the old software $(53.93 \%$ reported $)(P<0.000 \mathrm{I})$.

- Forced spirometry monitoring compliance $(71.97 \%$ reported) than those on the old software $(54.51 \%$ reported) $(\mathrm{P}<0.000 \mathrm{I})$. 
Table 4 Summary Of Subset Daily Adherence Scores

\begin{tabular}{|c|c|c|c|c|}
\hline $\begin{array}{l}\text { Subject } \\
\text { ID }\end{array}$ & $\begin{array}{l}\text { Software } \\
\text { Version }\end{array}$ & $\begin{array}{l}\text { Days } \\
\text { Monitored }\end{array}$ & $\begin{array}{l}\text { Adherence } \\
\text { Score/Day }\end{array}$ & P-value \\
\hline 1004 & $\begin{array}{l}\text { New } \\
\text { Old }\end{array}$ & $\begin{array}{l}64 \\
287\end{array}$ & $\begin{array}{l}5.34 \\
3.95\end{array}$ & \multirow[t]{5}{*}{0.009} \\
\hline 1006 & $\begin{array}{l}\text { New } \\
\text { Old }\end{array}$ & $\begin{array}{l}50 \\
313\end{array}$ & $\begin{array}{l}5.68 \\
2.34\end{array}$ & \\
\hline 1010 & $\begin{array}{l}\text { New } \\
\text { Old }\end{array}$ & $\begin{array}{l}67 \\
283\end{array}$ & $\begin{array}{l}5.54 \\
3.44\end{array}$ & \\
\hline 1015 & $\begin{array}{l}\text { New } \\
\text { Old }\end{array}$ & $\begin{array}{l}249 \\
117\end{array}$ & $\begin{array}{l}5.16 \\
1.93\end{array}$ & \\
\hline 1017 & $\begin{array}{l}\text { New } \\
\text { Old }\end{array}$ & $\begin{array}{l}280 \\
102\end{array}$ & $\begin{array}{l}4.24 \\
3.21\end{array}$ & \\
\hline
\end{tabular}

Notes: A subset analysis was performed using data from five participants who used both versions of the software. A paired $t$-test was used to compare if the percentage of recorded maneuvers or averaged adherence score was different between the new and the old software. These participants had a mean (SD) adherence score of $5.19(0.57)$ for the new software versus $2.97(0.82)$ for the old software $(P=0.01)$.

Table 5). Subset adherence to daily physical activity reporting by CLEAR-Ex increased from 49.7 (14.3) \% to 87.0 (9.8) \% ( $\mathrm{P}=0.012$, Table 5). Subset adherence to slow spirometry increased from 49.0 (13.7) \% to 87.0 (9.8) \% $(\mathrm{P}=0.010$, Table 5). Subset adherence to forced spirometry increased from 49.7 (12.4) \% to 86.9 (9.9) \% ( $\mathrm{P}=0.006$, Table 5). In addition to improved adherence, time spent to complete the daily monitoring routine was decreased from $12.7 \pm 5.4$ (4.0-38.0) minutes to $6.5 \pm 6.2(3.0-12.0)$ minutes $(\mathrm{P}<0.001)$.

\section{Occurrence Of Exacerbations}

Event rates per patient-year for exacerbations were: selfreported 0.42, 2/3 Anthonisen Criteria (AC) 0.42, modified AC 2.23, systemic corticosteroid use 0.56 , and antibiotic use 0.56 .

\section{Discussion}

The CLEAR study was primarily a feasibility study of remote monitoring of COPD patients in their homes, in which we evaluated the possibility of capturing daily symptoms, treatment adherence, self-reported activity, spirometry, oxygenation and physical activity by accelerometry. We recruited a total of 17 subjects undergoing home monitoring. These subjects collectively provided 2,618 days of data from home monitoring or 7.17 patient-years. We monitored some patients for up to 12 months but for most the burden of daily monitoring did not allow this goal to be accomplished. Therefore, given currently available technologies, remote patient monitoring might be viewed as a valuable means of short-term monitoring in selected patients such as those recently discharged from hospital after a COPD exacerbation. ${ }^{22}$

Our study was successful in several respects. Firstly, we were able to refine the software for remote data capture which improved overall patient adherence to data recording from $50.1 \%$ to $69.4 \%$ and reduced the time spent to complete the daily monitoring routine from $12.7 \pm 5.4$ to $6.5 \pm 6.2$ mins $(\mathrm{P}<0.001)$. Adherence to pulse oximetry, symptom reporting, medication reporting, physical activity reporting, slow spirometry and forced spirometry all increased significantly $(\mathrm{P}<0.001)$. Secondly, we discovered the value of SPC as a means of identifying criteria for prediction events and were able to replace the overly burdensome ATS criteria for the performance of spirometry $^{17}$ with a statistically defensible routine for daily monitoring that views all daily measurements as a continuous data set. Thirdly, we were able to determine event rates (per patient-year) for each of our predictors as well as for exacerbations defined by several different criteria. Fourthly, we were able to associate certain predictors derived from remote monitoring with exacerbations.

Statistical process control involves the use of simple statistical tools, such as histograms and flow charts, to determine control limits. ${ }^{23}$ The advantages of this methodology are that it enables the determination of a stable baseline from a longitudinal data set and then sets control limits to detect deviations from the baseline. ${ }^{24}$ Application of SPC enabled us to set clinically meaningful thresholds around our data and to examine interactions between these thresholds. Most importantly, SPC allowed us to interpret daily spirometric values as a continuous data set without needing to apply the traditional ATS criteria for the performance of spirometry as might be applicable to a single set of measurements at a single point in time. ${ }^{17}$ This change was mainly responsible for the reduced daily monitoring time and the increased patient adherence to capturing the various data elements.

Early detection of COPD exacerbations by remote patient monitoring was a goal of this research study. To date, there have been various attempts to accomplish this goal but there is as yet no consensus and to what should be measured and what thresholds should be chosen to trigger an intervention. One study monitored breathing frequency for 3 months in 89 COPD patients. ${ }^{25}$ The investigators identified Increases in breathing frequency of $4.4 /$ minute 
Table 5 Breakdown Of Subset Adherence To Each Component Of Remote Monitoring

\begin{tabular}{|c|c|c|c|c|c|c|}
\hline $\begin{array}{l}\text { Component Of Remote } \\
\text { Monitoring }\end{array}$ & $\begin{array}{l}\text { Subject } \\
\text { ID }\end{array}$ & $\begin{array}{l}\text { Software } \\
\text { Version }\end{array}$ & $\begin{array}{l}\text { Days } \\
\text { Monitored }\end{array}$ & $\begin{array}{l}\text { Reported } \\
\text { (n) }\end{array}$ & $\begin{array}{l}\text { Reported } \\
\text { (\%) }\end{array}$ & P-value \\
\hline \multirow[t]{10}{*}{ Oxygen Saturation $\left(\mathrm{SpO}_{2}\right)$} & 1004 & New & 64 & 57 & 89.1 & \multirow[t]{10}{*}{0.006} \\
\hline & & & & & 00.0 & \\
\hline & 1006 & New & 50 & 44 & 88.0 & \\
\hline & & Old & 313 & 119 & 38.0 & \\
\hline & 1010 & New & 67 & 61 & 91.0 & \\
\hline & & Old & 283 & 161 & 56.9 & \\
\hline & 1015 & New & 249 & 204 & 81.9 & \\
\hline & & Old & 117 & 37 & 31.6 & \\
\hline & 1017 & New & 280 & 197 & 70.4 & \\
\hline & & Old & 102 & 53 & 52.0 & \\
\hline \multirow[t]{10}{*}{ Daily Symptom Reporting (CLEAR-Sx) } & 1004 & New & 64 & 57 & 89.1 & \multirow[t]{10}{*}{0.011} \\
\hline & & Old & 287 & 192 & 66.9 & \\
\hline & 1006 & New & 50 & 48 & 96.0 & \\
\hline & & Old & 313 & 120 & 38.3 & \\
\hline & 1010 & New & 67 & 62 & 92.5 & \\
\hline & & Old & 283 & 162 & 57.2 & \\
\hline & 1015 & New & 249 & 216 & 86.7 & \\
\hline & & Old & 117 & 38 & 32.5 & \\
\hline & 1017 & New & 280 & 198 & 70.7 & \\
\hline & & Old & 102 & 56 & 54.9 & \\
\hline \multirow[t]{10}{*}{ Daily Symptom Reporting (CLEAR-Rx) } & 1004 & New & 64 & 57 & 89.1 & \multirow[t]{10}{*}{0.011} \\
\hline & & Old & 287 & 192 & 66.9 & \\
\hline & 1006 & New & 50 & 48 & 96.0 & \\
\hline & & Old & 313 & 120 & 38.3 & \\
\hline & 1010 & New & 67 & 62 & 92.5 & \\
\hline & & Old & 283 & 162 & 57.2 & \\
\hline & 1015 & New & 249 & 216 & 86.7 & \\
\hline & & Old & 117 & 38 & 32.5 & \\
\hline & 1017 & New & 280 & 198 & 70.7 & \\
\hline & & Old & 102 & 56 & 54.9 & \\
\hline \multirow[t]{10}{*}{ Daily Symptom Reporting (CLEAR-Ex) } & 1004 & New & 64 & 57 & 89.1 & \multirow[t]{10}{*}{0.012} \\
\hline & & Old & 287 & 191 & 66.6 & \\
\hline & 1006 & New & 50 & 48 & 96.0 & \\
\hline & & Old & 313 & 117 & 37.4 & \\
\hline & 1010 & New & 67 & 62 & 92.5 & \\
\hline & & Old & 283 & 162 & 57.2 & \\
\hline & 1015 & New & 249 & 216 & 86.7 & \\
\hline & & Old & 117 & 38 & 32.5 & \\
\hline & 1017 & New & 280 & 198 & 70.7 & \\
\hline & & Old & 102 & 56 & 54.9 & \\
\hline
\end{tabular}

(Continued) 
Table 5 (Continued).

\begin{tabular}{|c|c|c|c|c|c|c|}
\hline $\begin{array}{l}\text { Component Of Remote } \\
\text { Monitoring }\end{array}$ & $\begin{array}{l}\text { Subject } \\
\text { ID }\end{array}$ & $\begin{array}{l}\text { Software } \\
\text { Version }\end{array}$ & $\begin{array}{l}\text { Days } \\
\text { Monitored }\end{array}$ & $\begin{array}{l}\text { Reported } \\
\text { (n) }\end{array}$ & $\begin{array}{l}\text { Reported } \\
\text { (\%) }\end{array}$ & P-value \\
\hline \multirow[t]{5}{*}{ Slow Spirometry Monitoring } & 1004 & $\begin{array}{l}\text { New } \\
\text { Old }\end{array}$ & $\begin{array}{l}64 \\
287\end{array}$ & $\begin{array}{l}57 \\
18 \mid\end{array}$ & $\begin{array}{l}89.1 \\
63.1\end{array}$ & \multirow[t]{5}{*}{0.010} \\
\hline & 1006 & $\begin{array}{l}\text { New } \\
\text { Old }\end{array}$ & $\begin{array}{l}50 \\
313\end{array}$ & $\begin{array}{l}48 \\
|2|\end{array}$ & $\begin{array}{l}96.0 \\
38.7\end{array}$ & \\
\hline & 1010 & $\begin{array}{l}\text { New } \\
\text { Old }\end{array}$ & $\begin{array}{l}67 \\
283\end{array}$ & $\begin{array}{l}62 \\
163\end{array}$ & $\begin{array}{l}92.5 \\
57.6\end{array}$ & \\
\hline & 1015 & $\begin{array}{l}\text { New } \\
\text { Old }\end{array}$ & $\begin{array}{l}249 \\
117\end{array}$ & $\begin{array}{l}216 \\
36\end{array}$ & $\begin{array}{l}86.7 \\
30.8\end{array}$ & \\
\hline & 1017 & $\begin{array}{l}\text { New } \\
\text { Old }\end{array}$ & $\begin{array}{l}280 \\
102\end{array}$ & $\begin{array}{l}198 \\
56\end{array}$ & $\begin{array}{l}70.7 \\
54.9\end{array}$ & \\
\hline \multirow[t]{5}{*}{ Forced Spirometry Monitoring } & 1004 & $\begin{array}{l}\text { New } \\
\text { Old }\end{array}$ & $\begin{array}{l}64 \\
287\end{array}$ & $\begin{array}{l}57 \\
187\end{array}$ & $\begin{array}{l}89.1 \\
65.2\end{array}$ & \multirow[t]{5}{*}{0.006} \\
\hline & 1006 & $\begin{array}{l}\text { New } \\
\text { Old }\end{array}$ & $\begin{array}{l}50 \\
313\end{array}$ & $\begin{array}{l}48 \\
135\end{array}$ & $\begin{array}{l}96.0 \\
43.1\end{array}$ & \\
\hline & 1010 & $\begin{array}{l}\text { New } \\
\text { Old }\end{array}$ & $\begin{array}{l}67 \\
283\end{array}$ & $\begin{array}{l}62 \\
164\end{array}$ & $\begin{array}{l}92.5 \\
58.0\end{array}$ & \\
\hline & 1015 & $\begin{array}{l}\text { New } \\
\text { Old }\end{array}$ & $\begin{array}{l}249 \\
117\end{array}$ & $\begin{array}{l}216 \\
39\end{array}$ & $\begin{array}{l}86.7 \\
33.3\end{array}$ & \\
\hline & 1017 & $\begin{array}{l}\text { New } \\
\text { Old }\end{array}$ & $\begin{array}{l}280 \\
102\end{array}$ & $\begin{array}{l}197 \\
50\end{array}$ & $\begin{array}{l}70.4 \\
49.0\end{array}$ & \\
\hline
\end{tabular}

Notes: For each component of remote monitoring, a subset analysis was performed using data from five participants who used both versions of the software. A paired $t$-test was used to compare if the percentage of recorded maneuvers or averaged adherence score was different between the new and the old software.

- Oxygen saturation monitoring: mean (SD) adherence score of 84.1 (8.4) \% for the new software versus 49.0 (I4.2) \% for the old software ( $P=0.006)$.

- Daily symptoms reporting: mean (SD) adherence score of $87.0(9.8) \%$ for the new software versus 50.0 (I4.2) \% for the old software (P=0.0II).

- Daily treatment reporting: mean (SD) adherence score of $87.0(9.8) \%$ for the new software versus $50.0(I 4.2) \%$ for the old software (P=0.0II).

- Daily activity reporting: mean (SD) adherence score of $87.0(9.8) \%$ for the new software versus 49.7 (I4.3) \% for the old software (P=0.0I2).

- Slow spirometry monitoring: mean (SD) adherence score of $87.0(9.8) \%$ for the new software versus 49.0 (I3.7) \% for the old software (P=0.010).

- Forced spirometry monitoring: mean (SD) adherence score of 86.9 (9.9) \% for the new software versus 49.7 (I2.4) \% for the old software ( $P=0.006)$.

$24 \mathrm{hrs}$ before hospitalization and 2.3/minute $48 \mathrm{hrs}$ before hospitalization.

In our study, the most frequently occurring of the chosen predictors were a fall on $\mathrm{SpO}_{2}$ below $90 \%$ and increased used of rescue inhaled short-acting bronchodilator therapy. Interestingly, these predictors were fairly simple and raise the question as to what spirometry may add in terms of assessing exacerbations. However, all of the predictors, including decreases in oxygenation, spirometry and physical activity, and increases in inhaled short-acting bronchodilator use occurred more often than did exacerbations defined using conventional criteria. The real-world experience of the COPD patient is probably more accurately characterized by this spectrum of daily measures than by conventional definitions of exacerbations. Indeed, daily monitoring could provide evidence that links more convincingly to longer-term outcomes such as disease progression, debility and death. Our study was obviously small and only exploratory and much larger-scale investigations will be needed to establish these connections, if they exist.

\section{Conclusion}

In summary, we successfully implemented remote monitoring for COPD patients in their homes. We have demonstrated the feasibility of the approach and improved the functionality of the apparatus used for this purpose. We have suggested various parameters that could be used to monitor COPD patients and suggested methods to define events from these measures. For example, we recommend the use of statistical process control to reduce the burden of repeated spirometric maneuvers. Due to the relatively 
small number of enrolled subjects and even smaller number of exacerbations, we were unable to evaluate the effects of remote patient monitoring on the cost of healthcare utilization. Remote monitoring in the home might not work for all COPD patients; however, we believe there is value in developing these techniques in high-risk patients such as those with a history of repeated exacerbations and those who have recently been discharged from hospital following a COPD exacerbation. A randomized controlled trial would be needed to establish that the benefit from this kind of monitoring is at least equivalent if not better to other home monitoring already being used.

\section{Disclosure}

During this study, $\mathrm{CBC}$ received consulting fees from eResearch Technologies Inc (ERT) for serving as Medical Director of their Clinical Services Division, also reports grants from eResearch Technologies, personal fees from GlaxoSmithKline, non-financial support from Equinox Fitness Clubs, personal fees from PulmonX, outside the submitted work. Mr Michael Taylor reports Previously employed by the company whose product was used in the investigation. This investigation was funded by ERT, Inc. The authors report no other conflicts of interest in this study.

\section{References}

1. American Lung Association, Epidemiology and Statistics Unit Research and Health Education Division. Trends in COPD (chronic bronchitis and emphysema): morbidity and mortality. 2013. Available from: http://www.lung.org/finding-cures/our-research/trend-reports/ copd-trend-report.pdf. Accessed January 6, 2014.

2. Global Initiative for Chronic Obstructive Lung Disease. Global strategy for diagnosis, management, and prevention of chronic obstructive pulmonary disease. 2013. Available from: http://www.goldcopd.org/uploads/ users/files/GOLD_Report_2013_Feb20.pdf. Accessed January 6, 2014.

3. World Health Organization. World health statistics 2008. 2008. Available from: http://www.who.int/whosis/whostat/EN_WHS08 Full.pdf. Accessed January 6, 2014.

4. Anzueto A, Leimer I, Kesten S. Impact of frequency of COPD exacerbations on pulmonary function, health status and clinical outcomes. Int $J$ Chron Obstruct Pulmon Dis. 2009;4:245-251.

5. Halpin DM, Decramer M, Celli B, Kesten S, Liu D, Tashkin DP. Exacerbation frequency and course of COPD. Int $J$ Chron Obstruct Pulmon Dis. 2012;7:653-661. doi:10.2147/COPD.S34186

6. Cote CG, Dordelly LJ, Celli BR. Impact of COPD exacerbations on patient-centered outcomes. Chest. 2007;131(3):696-704. doi:10.1378/ chest.06-1610

7. Wilkinson TM, Donaldson GC, Hurst JR, Seemungal TA, Wedzicha JA. Early therapy improves outcomes of exacerbations of chronic obstructive pulmonary disease. Am J Respir Crit Care Med. 2004;169(12):1298-1303. doi:10.1164/rccm.200310-1443OC
8. Bui AL, Fonarow GC. Home monitoring for heart failure management. J Am Coll Cardiol. 2012;59(2):97-104. doi:10.1016/j. jacc.2011.09.044

9. Pandor A, Gomersall T, Stevens JW, et al. Remote monitoring after recent hospital discharge in patients with heart failure: a systematic review and network meta-analysis. Heart. 2013;99(23):1717-1726. doi:10.1136/heartjnl-2013-303811

10. Lindgren BR, Finkelstein SM, Prasad B, et al. Determination of reliability and validity in home monitoring data of pulmonary function tests following lung transplantation. Res Nurs Health. 1997;20 (6):539-550.

11. Madsen F, Ulrik CS, Dirksen A, et al. Patient-administered sequential spirometry in healthy volunteers and patients with alpha 1-antitrypsin deficiency. Respir Med. 1996;90(3):131-138. doi:10.1016/s09546111(96)90154-7

12. Seemungal TA, Donaldson GC, Bhowmik A, Jeffries DJ, Wedzicha JA. Time course and recovery of exacerbations in patients with chronic obstructive pulmonary disease. Am J Respir Crit Care Med. 2000;161(5):1608-1613. doi:10.1164/ajrccm.161.5.9908022

13. Sund ZM, Powell T, Greenwood R, Jarad NA. Remote daily real-time monitoring in patients with COPD-a feasibility study using a novel device. Respir Med. 2009;103(9):1320-1328. doi:10.1016/j.rmed.2009. 03.017

14. Vestbo J, Hurd SS, Agusti AG, et al. Global strategy for the diagnosis, management, and prevention of chronic obstructive pulmonary disease: GOLD executive summary. Am J Respir Crit Care Med. 2013;187(4):347-365. doi:10.1164/rccm.201204-0596PP

15. Hankinson JL, Odencrantz JR, Fedan KB. Spirometric reference values from a sample of the general U.S. population. Am J Respir Crit Care Med. 1999;159(1):179-187. doi:10.1164/ajrccm.159.1.9712108

16. Miller MR, Crapo R, Hankinson J, et al. General considerations for lung function testing. The European Respiratory Journal. 2005;26 (1):153-161. doi:10.1183/09031936.05.00034505

17. Miller MR, Hankinson J, Brusasco V, et al. Standardisation of spirometry. Eur Respir J. 2005;26(2):319-338. doi:10.1183/09031936. 05.00034805

18. Ware J Jr., Kosinski M, Keller SD. A 12-Item Short-Form Health Survey: construction of scales and preliminary tests of reliability and validity. Med Care. 1996;34(3):220-233. doi:10.1097/00005650199603000-00003

19. Jones PW, Harding G, Berry P, Wiklund I, Chen WH, Kline Leidy N. Development and first validation of the COPD Assessment Test. Eur Respir J. 2009;34(3):648-654. doi:10.1183/09031936.00102509

20. Jones PW, Quirk FH, Baveystock CM, Littlejohns P. A self-complete measure of health status for chronic airflow limitation. The St. George's Respiratory Questionnaire. Am Rev Respir Dis. 1992;145 (6):1321-1327. doi:10.1164/ajrccm/145.6.1321

21. Anthonisen NR, Manfreda J, Warren CP, Hershfield ES, Harding GK, Nelson NA. Antibiotic therapy in exacerbations of chronic obstructive pulmonary disease. Ann Intern Med. 1987;106(2):196-204. doi:10.7326/0003-4819-106-2-196

22. Ding H, Karunanithi M, Kanagasingam Y, Vignarajan J, Moodley Y. A pilot study of a mobile-phone-based home monitoring system to assist in remote interventions in cases of acute exacerbation of COPD. J Telemed Telecare. 2014;20(3):128-134. doi:10.1177/1357633X14527715

23. Pfadt A, Wheeler DJ. Using statistical process control to make databased clinical decisions. J Appl Behav Anal. 1995;28(3):349-370. doi:10.1901/jaba.1995.28-349

24. Pfadt A, Cohen IL, Sudhalter V, Romanczyk RG, Wheeler DJ. Applying statistical process control to clinical data: an illustration. $J$ Appl Behav Anal. 1992;25(3):551-560. doi:10.1901/jaba.1992.25-551

25. Yanez AM, Guerrero D, Perez de Alejo R, et al. Monitoring breathing rate at home allows early identification of COPD exacerbations. Chest. 2012;142(6):1524-1529. doi:10.1378/chest.11-2728 


\section{Publish your work in this journal}

The International Journal of COPD is an international, peer-reviewed journal of therapeutics and pharmacology focusing on concise rapid reporting of clinical studies and reviews in COPD. Special focus is given to the pathophysiological processes underlying the disease, intervention programs, patient focused education, and self management protocols. This journal is indexed on PubMed Central, MedLine and CAS. The manuscript management system is completely online and includes a very quick and fair peer-review system, which is all easy to use. Visit http://www.dovepress.com/testimonials.php to read real quotes from published authors. 